\title{
Effects of sediment organics, detrital input, and temperature on demography, production, and body size of a deposit feeder
}

\author{
Jeffrey S. Levinton, Steven Stewart \\ Department of Ecology and Evolution, State University of New York at Stony Brook, Stony Brook, New York 11794, USA
}

\begin{abstract}
In spring, organic detritus enters temperate marine nearshore habitats during a period of changing temperature and often shifting detrital quality. We investigated the interacting roles of sedimentary organic matter, detrital quality (Spartina versus UIva input), and varying temperature on the population dynamics and biomass productivity of the common nearshore oligochaete Paranais litoralis. During the phase of population increase, detrital input had the same positive effect on population size, irrespective of the specific detrital type or temperature. Later, however, the populations overexploited available resources, and crashes occurred in the order: high temperature-Spartina, low temperature-Spartina, high temperature-Ulva, low temperature-Ulva. In contrast, biomass productivity was negatively affected by temperature. Carbon and nitrogen analyses of the sediment, detritus, and worms were used to calculate the nutritional value of the sedimentary carbon and nitrogen. At $15^{\circ} \mathrm{C}$, $0.8 \%$ of the nitrogen in the sediment was usable by the worms, while the conversion efficiency on detritus was 20 to $30 \%$. For carbon, about $0.2 \%$ of the sediment was converted, whereas about $5 \%$ of detrital carbon was converted. These numbers are somewhat lower at $25^{\circ} \mathrm{C}$. Results suggest that the overwhelming majority of carbon and nitrogen in the sediment is useless for deposit feeder nutrition. The large absolute amount, however, still may subsidize considerable deposit feeder production. In effect, a small percentage conversion, multiplied by a large availability, results in a considerable yield from the sedimentary organic matter. Pulses of detrital addition, however, may be nutritionally more valuable.
\end{abstract}

\section{INTRODUCTION}

In temperate habitats, detrital supply is rarely evenly dispersed throughout the year. In the subtidal, detrital supply from the phytoplankton often precedes the late spring, a time when temperature, animal activity, and microbial activity all increase in concert (e.g. Rudnick \& Oviatt 1986). As detrital material is mineralized, microbes and deposit feeders probably compete for nutrients from this potential food supply. In a mixed estuary, detrital supply may be depressed in summer, but the metabolic demand of benthic animals will still be elevated, owing to high temperature. Thus an understanding of the interacting roles of temperature and detrital supply is important to understanding benthic dynamics in detritus-based nearshore temperate ecosystems (Levinton 1988).

It is our objective in this article to estimate the contribution of non-living sediment carbon and sediment nitrogen from sedimentary organic matter to the production of deposit feeders. We report here on the experimental response of laboratory populations of the common salt-marsh oligochaete Paranais litoralis to the addition of 2 different detrital types to a salt marsh sediment, as a function of temperature. $P$. litoralis is a major component of the benthos in Long Island Sound and southern New England salt marsh mudflats, and in June usually increases to dominance, followed by a typically precipitous decline (Levinton \& Stewart 1982, Stewart unpubl.). In some years, a fall peak also occurs, and both peaks seem correlated with the supply of detritus derived from either the green seaweed Ulva rotundata or the cordgrass Spartina alterniflora. Consequently, we chose both plants as sources of detritus for our experiments. Our results also permit an estimate of the utility of the sedimentary organic matter (SOM), and the degree of conversion of detrital nitrogen and carbon into animal tissue. 


\section{MATERIALS AND METHODS}

Sediment was collected from Flax Pond, Long Island, New York, USA, on 1 April 1987. It was washed through a $1 \mathrm{~mm}$ sieve and the $<1 \mathrm{~mm}$ fraction retained for the experiment. The sediment was stored at $-22^{\circ} \mathrm{C}$ until the initiation of the experiment on 3 April.

The Paranais litoralis used to initiate the experiment were obtained from laboratory cultures (kept at $15^{\circ} \mathrm{C}$ ) which had been started from worms collected from Flax Pond. Spartina alterniflora was collected green from Flax Pond, dried at $40^{\circ} \mathrm{C}$ and ground to particles less than $125 \mu \mathrm{m}$ particle size. Ulva rotunda was likewise collected from Flax Pond, dried at $40^{\circ} \mathrm{C}$ and ground to particles less than $125 \mu \mathrm{m}$. Both were collected in June 1986 and stored at $-22^{\circ} \mathrm{C}$ until the time of the experiment.

Six 30 gallon (1141) Instant Ocean brand aquaria were set up with filtered natural seawater collected from West Meadow Creek (located near Flax Pond). Salinity was maintained at ca 30 . Three of the tanks were randomly assigned to be maintained at $25^{\circ} \mathrm{C}$ and the remaining 3 were maintained at $15^{\circ} \mathrm{C}$. Ten $15.4 \mathrm{~cm}$ diameter Petri dishes containing $100 \mathrm{ml}$ of thawed sediment were placed in each aquarium. Ten Paranais litoralis were added to each dish.

We added $250 \mathrm{mg}$ of ground Spartina to each dish in one randomly selected $15^{\circ} \mathrm{C}$ tank and in one randomly selected $25^{\circ} \mathrm{C}$ tank. We added $250 \mathrm{mg}$ of Ulva to each dish in another randomly selected $15^{\circ} \mathrm{C}$ tank and a $25^{\circ} \mathrm{C}$ tank. This amount of detritus corresponds to the average dry weight standing stock of Ulva on the mudflat, just before the onset of summer senescence of the algae. The remaining 2 tanks (one at $15^{\circ} \mathrm{C}$ and one at $25^{\circ} \mathrm{C}$ ) had no detrital additions and we refer to them as the sediment-alone or control treatments. They are controls in the sense that the effect of detrital addition was measured against a background of sediment only On the first sampling ( $38 \mathrm{~d}$ ) an additional $250 \mathrm{mg}$ of Ulva or Spartina was added to each dish which had received that treatment initially.

Our sampling design was planned to allow statistical analysis by 2 -way analysis of variance (Sokal \& Rohlf 1981). The 2 factors are temperature (2 levels: 15 and $25^{\circ} \mathrm{C}$ ) and detrital addition ( 3 levels: sediment-only or control; Ulva addition; and Spartina addition). Potential interaction effects between temperature and detrital addition factors could thus be identified. Our experimental design invites a potential statistical problem, since each tank contains all replicates of a given detrital addition or sediment-only treatment. If there is a common tank effect, then the among-replicate variance is not an adequate estimate since the tank effect would bias the variance. This bias, known as pseudoreplication, can be estimated because we have 2 tanks for a given detrital treatment. If there are no significant interactions between temperature and detrital addition, then there is no problem with pseudoreplication. This turned out to be the case for the overwhelming majority of the 2-way ANOVAs we performed, and it is true of all the cases that we use to draw conclusions in this paper. Even in the rare exceptions, the interaction can be explained in terms of factors other than tank effects.

Sediment samples were taken periodically $(38,45$, $63,73,84,104 \mathrm{~d}$ ) after the start of the experiment. Two samples, each of ca 3 to $5 \mathrm{ml}$, were taken from each dish using a $50 \mathrm{ml}$ pipette and suction bulb. The end of the pipette was broken off to allow free access of the sediment particles. A sample was obtained by applying suction as the pipette was dragged across the sediment surface. The samples were placed in $15 \mathrm{ml}$ test tubes and allowed to settle for $1 / 2 h$, at which time the volume of the sediment in the sample was determined. The sediment was then sieved through a $250 \mu \mathrm{m}$ sieve and the worms retained were washed off and counted under a Zeiss dissecting microscope. All the sediment was collected for later replacement in the dish from which it had been obtained. This procedure allowed a determination of the number of worms per ml sediment and, by the appropriate multiplier, the number of worms per dish.

The first 2 Paranais litoralis from each dish were transferred to preweighed aluminum weighing boats after being bathed in a series of 3 distilled water baths for ca $30 \mathrm{~s}$ each to remove the salts. Four worms (combined from 2 dishes) were placed in each boat. There were 5 boats per treatment. They were dried at $40^{\circ} \mathrm{C}$ for a minimum of $3 \mathrm{~d}$ and then weighed to determine the dry weight per worm. The remaining worms collected from the sampling were separated by treatment and placed in $5 \%$ formalin.

Percent carbon, hydrogen, and nitrogen of the dried Paranais litoralis, Ulva, Spartina, and the sediment were determined using a Perkin-Elmer 240B CHN Analyzer. The sediment was analyzed whole, and the $<63 \mu \mathrm{m}$ fraction was determined separately. The $\%$ $\mathrm{C}: \mathrm{H}: \mathrm{N}$ composition ( $\pm \mathrm{SD}, n=3$ ) for the 3 materials was as follows:

$$
\begin{aligned}
& \text { Ulva: } \mathrm{C}=25.49 \pm 0.13 ; \mathrm{H}=4.77 \pm 0.05 ; \mathrm{N}= \\
& 2.53 \pm 0.07 . \\
& \text { Spartina: } \mathrm{C}=38.46 \pm 0.45 ; \mathrm{H}=5.42 \pm 0.05 ; \\
& \mathrm{N}=2.40 \pm 0.12 . \\
& \text { Sediment: } \mathrm{C}=4.08 \pm 0.27 ; \mathrm{H}=0.86 \pm 0.01 ; \\
& \mathrm{N}=0.33 \pm 0.02 . \\
& \text { Sediment }(<63 \mu \mathrm{m}): \mathrm{C}=2.50 \pm 0.13 ; \mathrm{H}= \\
& 0.65 \pm 0.06 ; \mathrm{N}=0.25 \pm 0.03 .
\end{aligned}
$$

Forty worms from each treatment for each sampling period were measured for length and largest width 
using a Scientific Applications Corporation sonic digitizer. The worms tended to curl up when preserved, so we measured the distance between 10 points along the length of the worm and added them to get total length. Biomass was determined by multiplying the dry weight per worm times the mean number of specimens for that treatment and sampling period.

Population responses could all be explained by asexual reproduction and mortality. Reproduction is asexual, both in the field and in the laboratory. Cocoons are never observed during the rapid spring population flush. Paranais litoralis reproduces asexually by naidian paratomy, a rapid form of reproduction where a zone of fission forms at a constant number of segments from the anterior end of the worm. A new worm does not bud off until a complete head is formed (Lasserre 1975). While chains of individuals can be formed, we never saw evidence of this and presume that a newly formed individual tended to bud off rapidly. Lengthfrequency distributions were always unimodal.

Our sampling design permitted an estimate of the conversion efficiency of nitrogen and carbon from sediment and detritus to worm. Because of the asexual and probably bipartite splitting, we take the population peak size to be an estimate of production. This assumes no mortality up to the peak, and no reproduction afterwards. While these assumptions may be somewhat unrealistic, the general conditions of the worms suggests that they were not seriously violated. During the period of population growth the worms looked healthy (large, many with fission marks) whereas during the decline individual weight decreased and reproduction was probably minimal. During the decline, we did not observe the fission marks characteristic of paratomy. Furthermore, during the decline, changes in biomass tracked changes in numbers. Thus the declines we observed were due to mortality, as opposed to a reduced splitting rate.

We can therefore use the following equation:

$$
P=C_{1} D_{1}+C_{S} S
$$

where $P=$ production; $c_{s}=$ conversion efficiency of the sedimentary organic carbon or nitrogen; $c_{i}=$ conversion efficiency of detrital type $i_{i} D_{1}=$ total detrital carbon or nitrogen added for detrital type $i$; and $S=$ the total sedimentary carbon or nitrogen. Using the sediment-only (control) conditions, we can calculate $c_{1}$ by subtraction, assuming that the conversion efficiency on the SOM is the same irrespective of the presence of a potentially much more labile detrital fraction. Our estimate of conversion directly from the sediment is thus probably something of an overestimate, when detritus is added. To calculate the conversion efficiency, we only considered the first pulse of detrital addition. It is likely that the second pulse did not contribute much to the worms' growth. After the population peak was reached, generally around the $45 \mathrm{~d}$ sampling period, the worms lost weight and the population declined (excepting the $15^{\circ} \mathrm{C}$ sediment-only treatment - see 'Results'). We may conclude therefore that the second pulse came too late; the worms had apparently surpassed some threshold of nutritional deprivation (with the exception of the sediment-only treatment at $15^{\circ} \mathrm{C}$ ). In any event, an alternative to our interpretation would be to divide by 2 the calculated conversion for the detrital additions. The conclusions concerning conversion of SOM are unaffected by these considerations.

\section{RESULTS}

\section{Population size}

Fig. 1 illustrates changes in population density of Paranais litoralis during the $104 \mathrm{~d}$ duration of the experiment (see also Table 1). In all treatments, there is a period of expansion and decline to eventual extinction. During the expansion, which we sampled at Days 38,45 , and 63 , detritus addition caused a strong
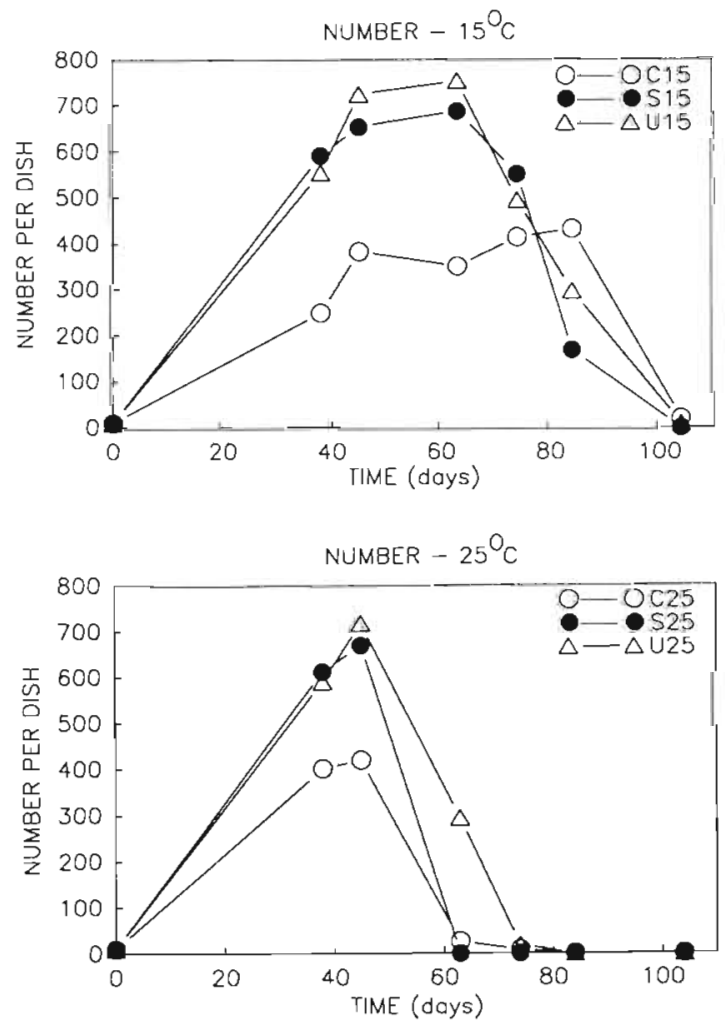

Fig. 1. Paranais litoralis. Changes in population size as a function of detrital addition and temperature. C15: Control, $15^{\circ} \mathrm{C}$; S15: Spartina, $15^{\circ} \mathrm{C}$; U15: Ulva, $15^{\circ} \mathrm{C}$; C25: Control, $25^{\circ} \mathrm{C}$; S25: Spartina, $25^{\circ} \mathrm{C}$; U25: Ulva, $25^{\circ} \mathrm{C}$. See Table 1 for statistical analysis 
Table 1. Paranais litoralis. Two-way ANOVA for numbers of worms per dish

\begin{tabular}{|clrll|}
\hline \multirow{2}{*}{ Day } & Source & df & F-ratio & \multicolumn{1}{c|}{$p$} \\
\hline \multirow{2}{*}{38} & Temperature & 1 & 3.32 & ns \\
& Nutrient & 2 & 19.97 & $<0.0001$ \\
& Temp. $\times$ Nut. & 2 & 1.31 & ns \\
\multirow{2}{*}{45} & Temperature & 1 & 0.08 & ns \\
& Nutrient & 2 & 12.40 & $<0.0001$ \\
& Temp. $\times$ Nut. & 2 & 0.43 & ns \\
63 & Temperature & 1 & 128.56 & $<0.0001$ \\
& Nutrient & 2 & 16.64 & $<0.0001$ \\
& Temp. $\times$ Nut. & 2 & 9.44 & $<0.0002$ \\
73 & Temperature & 1 & 315.61 & $<0.0001$ \\
& Nutrient & 2 & 2.48 & ns \\
& Temp. $\times$ Nut. & 2 & 1.95 & ns \\
84 & Temperature & 1 & 97.92 & $<0.0001$ \\
& Nutrient & 2 & 6.28 & $<0.0026$ \\
& Temp. $\times$ Nut. & 2 & 6.28 & $<0.0026$ \\
104 & Temperature & 1 & 18.70 & $<0.0001$ \\
& Nutrient & 2 & 0.90 & ns \\
& Temp. $\times$ Nut. & 2 & 1.24 & ns \\
\hline
\end{tabular}

increase in numbers relative to the sediment-only control, but there is no statistical difference between detrital types, or between temperatures for a given detrital type in the 2 main samplings of the increase, namely Days 38 and 45 (Table 1). During the decline, however, the effect of temperature was of great importance (Fig. 1). The $25^{\circ} \mathrm{C}$ treatments commenced their decline before the $15^{\circ} \mathrm{C}$ treatments (see also Table 1 ). At the higher temperature, the Spartina treatment showed more accelerated decline than the Ulva treatment. Such a detrital source difference did not occur at $15^{\circ} \mathrm{C}$; both populations declined at about the same time and rate (Fig. 1).

As mentioned, the sediment-only (control) treatments show lower population numbers. At $25^{\circ} \mathrm{C}$ the population reached a peak at 38 and $45 \mathrm{~d}$, and then became nearly extinct by the next sampling period (63 d) (Fig. 1). By contrast, at $15^{\circ} \mathrm{C}$ the population rose to about the same peak population size, but maintained this level from Day 45 to Day 84 , followed by a decline. As in the detrital addition treatments, the population at the lower temperature was longer lived. The temporal stability in the $15^{\circ} \mathrm{C}$ sediment-only case, however, was unique among all the treatments we analyzed. The stability at $15^{\circ} \mathrm{C}$ is the explanation for a significant interaction effect between detrital treatment effect and temperature at $63 \mathrm{~d}$ (Table 1). While such an interaction in theory can be explained by a 'tank effect' between the $15^{\circ} \mathrm{C}$ and $25^{\circ} \mathrm{C}$ sedimentonly treatments, we have independent evidence that it is in fact due to the apparent stability of the $15^{\circ} \mathrm{C}$ sediment-only treatment. One of us (S.S.) has done this particular experiment in the past and found exactly the same long-term stability of Paranais Iitoralis population numbers at $15^{\circ} \mathrm{C}$.

The generation time can be estimated if we assume dichotomous splitting. Since the distribution of length was always unimodal, and we did not see more than one fission zone in the worms, this assumption is justifiable. Under such an assumption, the number of generations $n$ can be calculated as follows:

$$
n=\frac{\log \left(N_{1} / N_{0}\right)}{\log (2)}
$$

where $N_{0}=$ initial number, and $N_{t}=$ number at time $t$. At peak population density under the $15^{\circ} \mathrm{C}$ Ulva treatment after $45 \mathrm{~d}$, the estimated number of doublings is about 6 .

\section{Biomass}

As was the case for population size, changes in biomass also reflected detrital input during the population increase (Fig. 2). The effects of temperature during this period, however, were also significant (Table 2). On sampling Day 45 , the biomass peak for most treatments, the $15^{\circ} \mathrm{C}$ treatments for Spartina and Ulva plus the $25^{\circ} \mathrm{C}$ Ulva treatment yielded the greatest biomass. The bio-
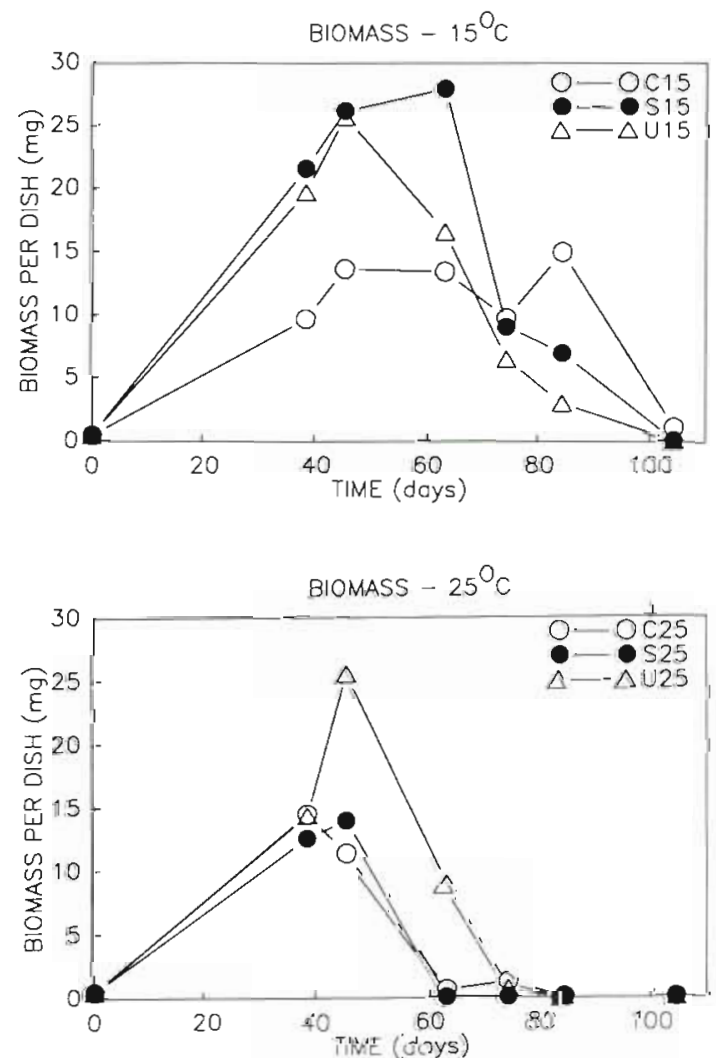

Fig. 2. Paranais litoralis. Changes in biomass as a function of temperature and detrital input. Symbols as in Fig. 1. See Table 2 for statistical analysis 
Table 2. Paranais litoralis. Two-way ANOVA for biomass of worms per dish

\begin{tabular}{|c|c|c|c|c|}
\hline Day & Source & $\mathrm{df}$ & F-ratio & $p$ \\
\hline \multirow[t]{3}{*}{38} & Temperature & 1 & 1.32 & ns \\
\hline & Nutrient & 2 & 1.67 & ns \\
\hline & Temp. $\times$ Nut. & 2 & 2.15 & ns \\
\hline \multirow[t]{3}{*}{45} & Temperature & 1 & 5.08 & $<0.0336$ \\
\hline & Nutrient & 2 & 12.50 & $<0.0002$ \\
\hline & Temp. $\times$ Nut & 2 & 2.93 & ns \\
\hline \multirow[t]{3}{*}{63} & Temperature & 1 & 32.87 & $<0.0001$ \\
\hline & Nutrient & 2 & 9.37 & $<0.0013$ \\
\hline & Temp. $\times$ Nut. & 2 & 0.88 & $\mathrm{~ns}$ \\
\hline \multirow[t]{3}{*}{73} & Temperature & 1 & 29.35 & $<0.0001$ \\
\hline & Nutrient & 2 & 2.06 & ns \\
\hline & Temp. $\times$ Nut. & 2 & 0.71 & ns \\
\hline \multirow[t]{3}{*}{84} & Temperature & 1 & $-{ }^{a}$ & - \\
\hline & Nutrient & 2 & 6.05 & $<0.0153$ \\
\hline & Temp. $\times$ Nut. & 2 & $-{ }^{\mathrm{a}}$ & - \\
\hline
\end{tabular}

mass of the $25^{\circ} \mathrm{C}$ Spartina treatment was nearly half this amount, while the biomasses of both the $15^{\circ} \mathrm{C}$ control and $25^{\circ} \mathrm{C}$ control treatments were lower still. During the following weeks of decline, the $25^{\circ} \mathrm{C}$ Ulva treatment fell
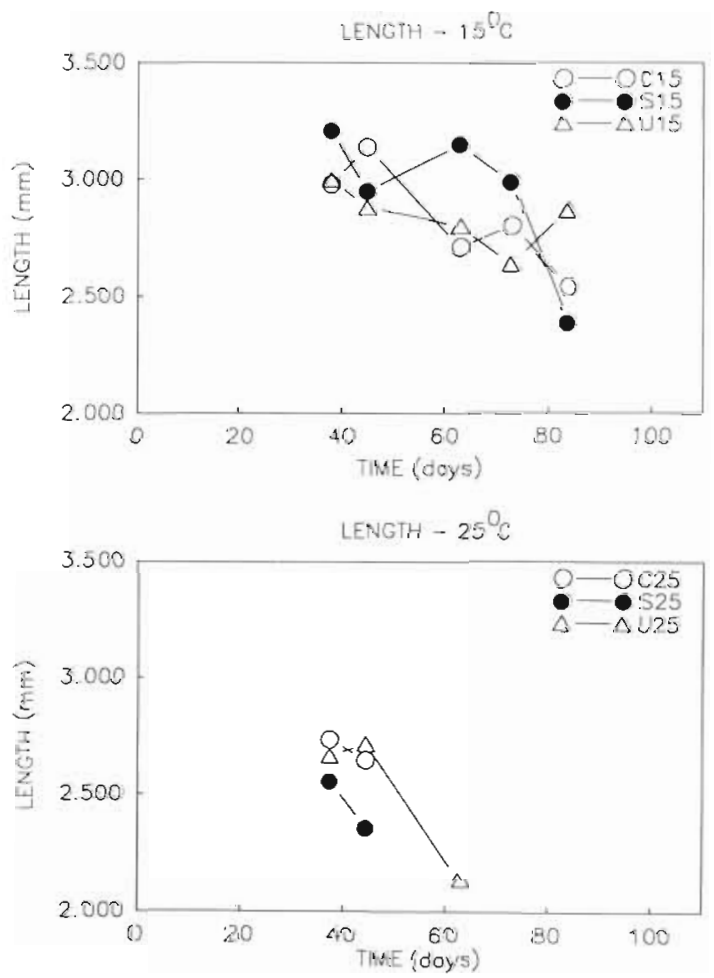

Fig. 3. Paranais litoralis. Changes in body length as a function of temperature and detrital input. Symbols as in Fig. 1. See Table 3 for statistical analysis more rapidly than the 2 other $15^{\circ} \mathrm{C}$ detrital treatments. The $25^{\circ} \mathrm{C}$ Spartina treatment differed only slightly from the sediment-only treatment. As in the data for population numbers, the $15^{\circ} \mathrm{C}$ sediment-only treatment seems to show a remarkable stability from Day 45 to Day 84 . Also of interest is the $15^{\circ} \mathrm{C}$ Spartina treatment, which reached higher peak biomass than the $15^{\circ} \mathrm{C}$ Ulva treatment. Throughout the experiment, there were no significant interaction effects between the detrital addition and temperature factors.

\section{Body size}

Trends in body length are illustrated in Fig. 3. Throughout the experiment, body length was consistently greater at $15^{\circ} \mathrm{C}$, irrespective of detrital treatment (2-way ANOVA, $p<0.0001$; Table 3$)$. For a given treatment, there was a generally modest decline in length during the entire experiment. Body weight also declined during the experiment, but more rapidly (Fig. 4). Body width more closely followed the trend for body weight. During the main period of population increase (Days 38 and 45), temperature had a much greater differentiating effect on weight than had detrital type (Table 4). Body weight was consistently greater at low temperature, whereas there was no significant
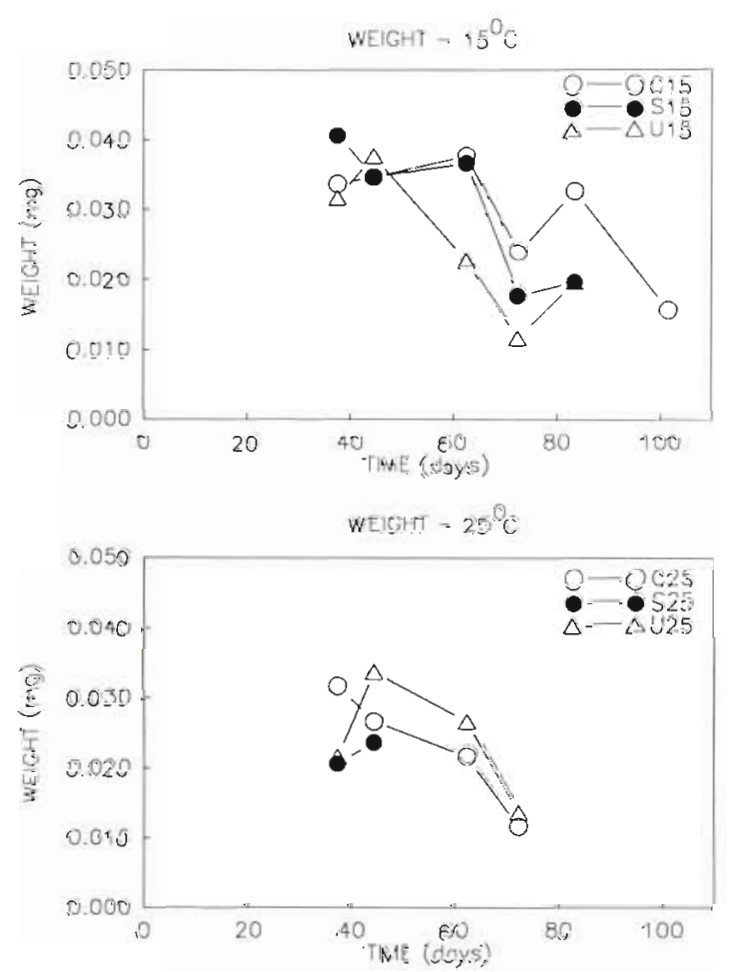

Fig. 4. Paranais litoralis. Changes in body weight as a function of temperature and detrital input. Symbols as in Fig. 1. See Table 4 for statistical analysis 
Table 3. Paranais litoralis. Two-way ANOVA for length of worms

\begin{tabular}{|c|c|c|c|c|}
\hline Day & Source & df & $F$-ratio & $p$ \\
\hline 38 & $\begin{array}{l}\text { Temperature } \\
\text { Nutrient } \\
\text { Temp. } \times \text { Nut. }\end{array}$ & $\begin{array}{l}1 \\
2 \\
2\end{array}$ & $\begin{array}{r}26.45 \\
0.14 \\
2.55\end{array}$ & $\begin{array}{l}<0.0001 \\
\text { ns } \\
\text { ns }\end{array}$ \\
\hline 45 & $\begin{array}{l}\text { Temperature } \\
\text { Nutrient } \\
\text { Temp. } \times \text { Nut. }\end{array}$ & $\begin{array}{l}1 \\
2 \\
2\end{array}$ & $\begin{array}{r}28.32 \\
3.17 \\
2.82\end{array}$ & $\begin{array}{l}<0.0001 \\
<0.0439 \\
\text { ns }\end{array}$ \\
\hline 63 & $\begin{array}{l}\text { Temperature } \\
\text { Nutrient } \\
\text { Temp. } \times \text { Nut. }\end{array}$ & $\begin{array}{l}1 \\
2 \\
2\end{array}$ & $\begin{array}{c}60.58 \\
7.93 \\
-{ }^{a}\end{array}$ & $\begin{array}{l}<0.0001 \\
<0.0001 \\
-\end{array}$ \\
\hline 73 & $\begin{array}{l}\text { Temperature } \\
\text { Nutrient } \\
\text { Temp. } \times \text { Nut. }\end{array}$ & $\begin{array}{l}1 \\
2 \\
2\end{array}$ & $\begin{array}{l}-b \\
3.19 \\
-b\end{array}$ & $\begin{array}{l}- \\
<0.0448 \\
-\end{array}$ \\
\hline 84 & $\begin{array}{l}\text { Temperature } \\
\text { Nutrient } \\
\text { Temp. } \times \text { Nut. }\end{array}$ & $\begin{array}{l}1 \\
2 \\
2\end{array}$ & $\begin{array}{c}-^{b} \\
10.00 \\
-a\end{array}$ & $\begin{array}{l}- \\
<0.0001 \\
-\end{array}$ \\
\hline $\begin{array}{l}\text { "Date } \\
\text { inter } \\
{ }^{\circ} \text { All } \\
\text { nutr }\end{array}$ & $\begin{array}{l}\text { not available fo } \\
\text { ction } \\
\text { orms dead at hic } \\
\text { ent effect only }\end{array}$ & & $\begin{array}{l}\text { ecluding } \\
\text { re, analy }\end{array}$ & $\begin{array}{l}\text { lculation o } \\
\text { possible for }\end{array}$ \\
\hline
\end{tabular}

difference among detrital and control treatments (Fig. 4).

\section{Conversion efficiency}

As mentioned in 'Materials and Methods', we used a subtraction technique, on the basis of certain assumptions, to estimate the conversion efficiency of organic nitrogen and carbon from sediment and detritus into worms. We have not traced the exact pathway, which may be through direct ingestion and assimilation of particulate organic matter (POM), or through ingestion of microbes benefiting from the POM. Reductions in conversion efficiency may be explained by increased mineralization (e.g. in the higher temperature treatments) as much as by reduced assimilation.

Table 5 shows the numbers required to make our calculations of conversion efficiency They include the total estimated carbon and nitrogen in the sediment and added detritus, and total nitrogen and carbon in the worms at $45 \mathrm{~d}$. To estimate conversion efficiency of the sediment, we divide the amount in the worms by the amount in the sediment. As can be seen, we estimate less than $1 \%$ efficiency. Previous evidence suggests that the worms are very inefficient at swallowing particles much larger than the arbitrary sedimentary silt threshold of $63 \mu \mathrm{m}$. Using mitrogen analyses of the $<63 \mu \mathrm{m}$ fraction, the conversion efficiency is still less than $1 \%$ for carbon, but is ca 2 to $3 \%$ for nitrogen. This can be explained by a proportional increase of the
Table 4. Paranais litoralis. Two-way ANOVA for weight of worms

\begin{tabular}{|c|c|c|c|c|}
\hline Day & Source & $\mathrm{df}$ & F-ratio & $p$ \\
\hline \multirow[t]{3}{*}{38} & Temperature & 1 & 12.58 & $<0.0017$ \\
\hline & Nutrient & 2 & 1.21 & ns \\
\hline & Temp. $\times$ Nut & 2 & 2.26 & $\mathrm{~ns}$ \\
\hline \multirow[t]{3}{*}{45} & Temperature & 1 & 11.23 & $<0.0027$ \\
\hline & Nutrient & 2 & 2.76 & ns \\
\hline & Temp. $\times$ Nut & 2 & 1.01 & ns \\
\hline \multirow[t]{3}{*}{63} & Temperature & 1 & 18.14 & $<0.0004$ \\
\hline & Nutrient & 2 & 5.97 & $<0.0093$ \\
\hline & Temp. $\times$ Nut & 2 & 26.85 & $<0.0001$ \\
\hline \multirow[t]{3}{*}{73} & Temperature & 1 & 2.08 & ns \\
\hline & Nutrient & 2 & 4.90 & $<0.0244$ \\
\hline & Temp. $\times$ Nut. & 2 & 4.54 & ns \\
\hline \multirow[t]{3}{*}{84} & Temperature & 1 & $-{ }^{a}$ & - \\
\hline & Nutrient & 2 & 4.57 & $<0.0334$ \\
\hline & Temp. $\times$ Nut & 2 & $-^{a}$ & - \\
\hline
\end{tabular}

nitrogen content of the $<63 \mu \mathrm{m}$ fraction, but a decrease in the carbon in this fraction, and may be due to carbon-rich larger particles derived from Spartina.

To obtain the conversion efficiency for the detrital treatments, we have subtracted the amount that presumably goes into the worms from the sediment (using the control or sediment-only treatment for an estimate). As can be seen, the conversion efficiency at $15^{\circ} \mathrm{C}$ for the detrital nitrogen treatments is 20 to $30 \%$, and about $5 \%$ for carbon. Thus for nitrogen, the detrital addition provided about 30 times the efficiency of that obtained from the sediment alone, and 25 times the efficiency for carbon. If we include the second experimental input of detrital material, these estimates would be cut by half, but they are still about one order of magnitude greater than the conversion on the material in the sediment.

At higher temperature, the sediment contributes still less to the worms. The cost of living at higher temperature can be estimated by comparing the conversion efficiencies. For the Spartina addition, the decrease in efficiency is much greater than for the Ulva addition, or for the sediment alone. It is not clear why Spartina is so much less valuable as a food at the higher temperature.

\section{DISCUSSION}

Detrital addition has been shown to strongly benefit benthic animal growth, particularly when the detritus is of high nitrogen content (Tenore 1975, 1977, Tenore et al. 1979). Even fairly nutritionally poor sources of 
Table 5. Inputs of nitrogen and carbon, and uptake by Paranais Litoralis, in terms of $\mathrm{mg}$ and percent conversion, relative to the input

\begin{tabular}{|c|c|c|c|c|}
\hline Inputs: & Carbon $(\mathrm{mg}) \pm(\mathrm{SD})$ & Nitrogen $(m g) \pm(S D)$ & & \\
\hline Total sediment & $1629.0(123.6)$ & $131.8(9.1)$ & & \\
\hline Sediment $<63 \mu \mathrm{m}$ & $398.7(40.5)$ & $39.9(5.3)$ & & \\
\hline Ulva & $63.3(0.3)$ & $6.3(0.2)$ & & \\
\hline Spartina & $96.2(1.9)$ & $6.0(0.3)$ & & \\
\hline Animal uptake: & Carbon $(\mathrm{mg}) \pm(\mathrm{SD})$ & Carbon $(\%)$ & Nitrogen $(\mathrm{mg}) \pm(\mathrm{SD})$ & Nitrogen (\%) \\
\hline \multicolumn{5}{|l|}{$15^{\circ} \mathrm{C}$} \\
\hline Whole sediment & $3.8(1.4)$ & 0.2 & $1.1(0.7)$ & 0.8 \\
\hline Sediment $<63 \mu \mathrm{m}$ & $3.8(1.4)$ & 1.0 & $1.1(0.7)$ & 2.6 \\
\hline Ulva & $7.1(1.4)$ & 5.2 & $2.4(0.5)$ & 21.3 \\
\hline Spartina & $9.5(0.4)$ & 5.9 & $2.8(0.4)$ & 28.9 \\
\hline \multicolumn{5}{|l|}{$25^{\circ} \mathrm{C}$} \\
\hline Whole sediment & $2.6(0.9)$ & 0.2 & $0.8(0.3)$ & 0.6 \\
\hline Sediment $<63 \mu \mathrm{m}$ & $2.6(0.9)$ & 0.7 & $0.8(0.3)$ & 1.8 \\
\hline Ulva & $5.3(1.5)$ & 4.2 & $1.6(0.5)$ & 6.3 \\
\hline Spartina & $3.3(1.8)$ & 0.7 & $1.2(0.8)$ & 13.1 \\
\hline
\end{tabular}

detritus may contribute to the growth of deposit feeders (Findlay \& Tenore 1982, Peterson et al. 1986). The proximate causes of this subsidy are not always well understood. In our experiments, we did not track the exact pathway of detrital addition to invertebrate growth. It is possible, for example, that the lowered conversion efficiency at high temperature was related to relatively rapid microbial and chemical degradation.

The fall senescence of Spartina alterniflora leaves is correlated with an increase in sediment microbial productivity (Rublee 1982), which may in turn benefit the deposit feeders. Experimental additions of Ulvaderived detritus can stimulate microalgal productivity, which is known to promote deposit-feeder growth (Levinton 1985). Labile seaweeds, such as Ulva and Gracilaria, are also more readily digestible directly (Findlay \& Tenore 1982). Isotopic analysis suggests that seaweeds pass more rapidly than seagrasses into the invertebrate consumer food web (Stephenson et al. 1986). While some Spartina mudflat deposit feeders resemble Spartina isotopically (Peterson et al. 1986), it is possible that microbes are an essential intermediate nutritional step. When Spartina detritus is fed to the polychaete Capitella capitata, more nitrogen is incorporated from associated microbes than from the detritus itself (Findlay \& Tenore 1982). Nevertheless, assimilation by detritivores of detritus derived from higher plants is in the range of ca 8 to $22 \%$ (summary in Valiela 1984).

In spring, temperature may not be initially a very important factor. In our experiments, detrital supply was at levels sufficient to support maximal production, even at the rather high temperature of $25^{\circ} \mathrm{C}$. In effect, sufficient food is available to counteract the possible negative effects of the additional metabolic load imposed by increasing temperature. Following this, however, temperature causes a dramatic effect; the high temperature populations decline far more rapidly than do those growing under lower temperatures. It is likely that the population overshoots the point where the next generation can be supported by available food. In our experiments, a second pulse of food failed to prevent a crash.

Our carbon and nitrogen budgets suggest that the organic material in the sediment is largely an untappable resource. Some of the material, however, was sufficiently labile to permit population increase. Moreover, at $15^{\circ} \mathrm{C}$, there was sufficient material for the population to remain stable over several sampling intervals. These results differ somewhat from those of Bianchi \& Levinton (1984), who found essentially no difference in growth of the mudsnail Hydrobia totteni between bleached and unbleached sediments; growth was explainable by microalgae. It is possible that the sediment, collected in April, had a recent influx of detritus. Also, the sediment we employed may have included meiofauna and other living organisms that could pass through a $1 \mathrm{~mm}$ sieve, were killed, and were then available to the deposit feeders. But our results are in accordance with those of Levinton et al. (1984) who reported that Paranais litoralis population growth is well correlated with sediment volume, as opposed to sediment surface area, which would be correlated with surface algal productivity.

Our results conform to Rice's (1982) conception of nearshore sediments as sinks of undigestible geopolymers. While these molecules may be broken down by microbes, which might in turn be digested and 
absorbed by deposit feeders, the rate constant is likely to be very low. The only practical sources of nutritive additions, therefore, must come from the steady state stock of microbes and the additions of detritus, that are either directly digestible or indirectly transformed by microbes into deposit feeder food. The low value of the sediment is comparable to the results of Rice et al. (1986) for another deposit feeder in another locality.

Our estimates for conversion efficiency of carbon and nitrogen are low but the absolute amounts of carbon and nitrogen in the sediment are high and a low efficiency still begets a relatively high reward. After all, peak population growth in the control sediments was on the order of one third to half that in the detrital experiments. In the sediment-only treatments, the ca 30 -fold lower carbon conversion efficiency from the sediment was made up by the ca 20 -fold greater availability in the sediment, relative to the detrital additions. Other considerations of nutritional quality would suggest that fresh detritus would be of far greater nutritional value. Essential fatty acids, for example, are relatively abundant in fresh green Spartina and in seaweed detritus (Tenore et al. 1984).

Our results suggest that a realistic model of interaction between organic matter and benthic production must include seasonal change in temperature, an estimate of the nutritional value of the organic matter in the sediment, and the value of the detritus that is added as a pulse, typically in the spring in temperate and boreal inshore waters. Several recent estimates suggest that the spring detrital pulse can explain a large part of the annual benthic production (Peinert et al. 1982, Christensen \& Kanneworf 1986). While these estimates are very useful, they ignore the important details of temperature effects, the rate of humification of detrital material into nutritionally unusable organic matter, and the role of the microbial community (which we have also ignored in this study). A realistic field study will have to incorporate seasonal sampling, and some sort of bioassay that can estimate the changing utility of the sediment to the benthos.

Acknowledgements. We thank Danjel Martinez, who assisted in the experiments. Supported by National Science Grant OCE8509539. Contribution no. 664 to the Graduate Studies in Ecology and Evolution.

\section{LITERATURE CITED}

Bianchi, T S., Levinton, J S. (1984). The importance of microalgae, bacteria and particulate organic matter in the somatic growth of Hydrobia totteni. J. mar Res. 42: $431-443$
Christensen, H., Kanneworf, E. (1986). Sedimentation of phytoplankton during a spring bloom in the Oresund. Ophelia 26: $109-122$

Findlay, S., Tenore, K. R. (1982). Nitrogen source for a detritivore: detritus substrate versus associated microbes. Science 218: 371-373

Lasserre, P. (1975). Chapter 2. Clitellata. In: Giese, A. C., Pearse, J. S. (eds.) Reproduction of marine invertebrates. V III. Annelids and echiurans. Academic Press, New York, p. $215-275$

Levinton, J. S. (1985). Complex interactions of a deposit feeder with its resources: roles of density, a competitor, and detrital addition in the growth and survival of the mudsnail Hydrobia totteni. Mar Ecol. Prog. Ser 22: 31-40

Levinton, J. S. (1988). Deposit feeding and coastal oceanography. In: Lopez, G. R., Taghon, G. L. (eds.) Ecology of marine deposit feeders. Springer-Verlag, Berlin, in press

Levinton, J. S., Bianchi, T S., Stewart, S. (1984). What is the role of particulate organic matter in benthic invertebrate nutrition? Bull. mar. Sci. 35: 270-282

Levinton, J. S., Stewart, S. (1982). Marine succession: the effect of two deposit-feeding gastropod species on the population growth of Paranais litoralis Muller 1784 (Oligochaeta). J. exp. mar Biol. Ecol. 59: 231-241

Peinert, R., Savre, A., Stegman, R., Stienen, C., Haardt, H., Smetacek, $V$ (1982). Dynamics of primary production and sedimentation in a coastal ecosystem. Neth. J. Sea Res. 16 : $276-289$

Peterson, B. J., Howarth, R. W., Garritt, R. H. (1986). Sulfur and carbon isotopes as tracers of salt-marsh organic matter flow. Ecology 67: 865-874

Rice, D. L. (1982). The detritus nitrogen problem: new observations and perspectives from organic geochemistry. Mar. Ecol. Prog. Ser. 9: 153-162

Rice, D. L., Bianchi, T. S., Roper, E. H. (1986). Experimental studies of sediment reworking and growth of Scoloplos spp (Orbiniidae: Polychaeta). Mar. Ecol. Prog. Ser. 30: 9-19

Rublee, P. A. (1982). Seasonal distribution of bacteria in salt marsh sediments in North Carolina. Estuar. coast. Shelf Sci. 15: $67-74$

Rudnick, D. T., Oviatt, C. A. (1986). Seasonal lags between organic carbon deposition and mineralization in marine sediments. J. mar. Res. 44: 815-837

Sokal, R. R., Rohlf, F. J. (1981). Biometry. W. H. Freeman, San Francisco

Stephenson, R. L., Tan, F. C., Mann, K. H. (1986). Use of stable carbon isotope ratios to compare plant material and potential consumers in a seagrass bed in Nova Scotia, Canada Mar. Ecol. Prog. Ser. 30: 1-7

Tenore, K. R. (1975). Detrital utilization by the polychaete Capitella capitata. J. mar. Res. 33: 261-274

Tenore, K. R. (1977). Growth of Capitella capitata cultured on various levels of detritus derived from different sources. Limnol. Oceanogr. 22: 936-941

Tenore. K. R., Hanson, R. B., Dornseif, B. E., Weiderhold, C. N. (1979). The effect of organic nitrogen supplement on the utilization of different sources of detritus. Limnol. Oceanogr. 24: 350-355

Tenore, K. R., Hanson, R. B., McClain, J., Maccubbin, A. E., Hodson, R. E. (1984). Changes in composition and nutritional value to a benthic deposit feeder of decomposing detritus pools. Bull. mar. Sci. 35: 299-311

Valiela, I. (1984). Marine ecological processes. Springer-Verlag, Berlin 